\title{
Comparison of Physical Activity Levels in Rheumatic Diseases
}

\section{Vergleich des körperlichen Aktivitätsniveaus bei rheumatischen Erkrankungen}

Authors

M. Acar ${ }^{1}$, E. Tonga², A. Daskapan³ ${ }^{3}$ M. Karataş ${ }^{4}$, A. Tekindal ${ }^{5}$

Affiliations

1 Faculty of Health Sciences, Department of Physiotherapy and Rehabilitation, Baskent University, Ankara, Turkey

2 Faculty of Health Sciences, Department of Physiotherapy and Rehabilitation, Marmara University, İstanbul, Turkey

3 Faculty of Health Sciences, Department of Physiotherapy and Rehabilitation, Kırıkkale University, Kırıkkale, Turkey

4 Faculty of Health Sciences, Department of Physiotherapy and Rehabilitation, Baskent University, Ankara, Turkey

5 Faculty of Medicine, Department of Biostatistics, İzmir, İmir University, Turkey

Key words

rheumatoid arthritis, osteoarthritis, fibromyalgia, physical activity, IPAQ

Schlüsselwörter

körperliche Aktivität, rheumatoide Arthritis, Arthrose,

Fibromyalgie

Bibliography

DOI https://doi.org/10.1055/s-0042-100614

Online-Publikation: 29.6.2016

Akt Rheumatol 2017; 42: 329-335

(c) Georg Thieme Verlag KG Stuttgart · New York

ISSN 0341-051X

Correspondence

Eda Tonga

Faculty of Health Sciences

Department of Physiotherapy and Rehabilitation

Marmara Üniversitesi

Sağlık Bilimleri Fakültesi

E5 yan yol üzeri

34865 Cevizli

Kartal, İstanbul

Tel.: + 90/216/3999 371, Fax: + 90/216/3996 242

eda-fzt@hotmail.com

\section{ABSTRACT}

Objectives The aim of this study was to evaluate levels of physical activity in patients with rheumatoid arthritis, osteoarthritis and fibromyalgia and to compare the results with both healthy subjects and each other.

Methods A group of 50 rheumatoid arthritis patients, 95 osteoarthritis patients, 82 fibromyalgia patients and 110 healthy subjects were included in this study. Physical activity levels were assessed by the International Physical Activity Questionnaire (IPAQ).

Results There were significant differences in walking and total physical activity scores in IPAQ between the rheumatoid arthritis (RA), osteoarthritis (OA), fibromyalgia (FMS) patients and the control group ( $p<0.05) .36 .6 \%$ of the fibromyalgia group, $28.4 \%$ of the osteoarthritis group, $38 \%$ of the rheumatoid arthritis group and $22.7 \%$ of the healthy subjects were found to be inactive. $45.1 \%$ of the fibromyalgia group, $42.1 \%$ of the osteoarthritis group, $46 \%$ of the rheumatoid arthritis group and $36.4 \%$ of the healthy subjects were found to be insufficiently active.

Conclusion As a result, when compared to healthy people, physical activity levels were significantly decreased in patients with rheumatoid arthritis, osteoarthritis, fibromyalgia. The decreases in the physical activity levels were clearer in patients with rheumatoid arthritis than in patients with osteoarthritis and fibromyalgia. Recommending regular physical activity should be integral to rheumatic disease management and walking offers a potentially accessible, inexpensive, and acceptable physical activity intervention.

\section{ZUSAMMENFASSUNG}

Zielsetzung Ziele dieser Studie waren die Beurteilung des körperlichen Aktivitätsniveaus bei Patienten mit rheumatoider Arthritis, Arthrose und Fibromyalgie sowie ein Vergleich der Ergebnisse zwischen den einzelnen Krankheitsbildern und mit gesunden Probanden.

Methoden Es wurden 50 Patienten mit rheumatoider Arthritis, 95 Patienten mit Arthrose, 82 Patienten mit Fibromyalgie sowie 110 gesunde Probanden in die Studie aufgenommen. Mithilfe des IPAQ-Fragebogens (,International Physical Activity Questionnaire“) wurde das körperliche Aktivitätsniveau ermittelt.

Ergebnisse Die Auswertung des IPAQ ergab bei den Scores für Gehen und körperliche Gesamtaktivität signifikante Unterschiede zwischen den Patienten mit rheumatoider Arthritis (RA), Arthrose („Osteoarthritis“, OA), Fibromyalgie (FMS) und der Kontrollgruppe ( $p<0,05)$. 36,6\% der Fibromyalgie-Patien- 
ten, 28,4\% der Arthrose-Patienten, $38 \%$ der Patienten mit rheumatoider Arthritis und $22,7 \%$ der gesunden Probanden wurden als inaktiv eingestuft. Bei 45,1\% der Fibromyalgie-Patienten, 42,1\% der Arthrose-Patienten, $46 \%$ der Patienten mit rheumatoider Arthritis und $36,4 \%$ der gesunden Probanden wurde ein unzureichendes Aktivitätsniveau festgestellt.

Schlussfolgerung Die Ergebnisse zeigen, dass das körperliche Aktivitätsniveau bei Patienten mit rheumatoider Arthritis, Arthrose oder Fi- bromyalgie im Vergleich zu gesunden Personen deutlich reduziert war. Bei Patienten mit rheumatoider Arthritis trat die Reduktion des körperlichen Aktivitätsniveaus stärker zutage als bei Patienten mit Arthrose oder Fibromyalgie. Regelmäßige körperliche Aktivität sollte im Rahmen der Behandlung rheumatischer Erkrankungen immer empfohlen werden. Hierfür bietet sich insbesondere das Walken an, da es potenziell quasi immer und überall möglich ist, keine hohen Kosten mit sich bringt und eine akzeptable Form der körperlichen Aktivität darstellt.

\section{Introduction}

Physical inactivity is a serious health problem worldwide, and a complication of rheumatic diseases, despite various data reporting the beneficial effects of physical activity (PA) on all-cause mortality [1,2]. PA is defined as body movement generated by skeletal muscles those results in energy expenditure [3]. Regarding the PA assessment methods used in studies, objective (accelerometers), subjective (surveys) and criteria methods (doubly labeled water technique) were observed. Accurate measurement of total daily energy expenditure is possible using the doubly labeled water technique [4]. However, this technique is not available in all centers. Alternative methods to assess PA include the use of triaxial accelerometers and patient questionnaires. Self-reported questionnaires that are subjective evaluations are not usually expensive by objective methods and can be applied easily by researchers [5], [6]. Pain, restricted mobility, fatigue, reduced muscle mass, strength and endurance, are more commonsymptoms inpatients with rheumatic diseases [7]. For these reasons, patients with rheumatic diseases usually face activity limitations, participation restrictions in their daily life, and have more sedentary life style than healthy people. The most important consequence of a sedentary lifestyle is reduction physical fitness and physical activity levels. Furthermore, diseases can result from being physically inactive, following activity limitations, and having participation restrictions results in. It is a vicious cycle that leads to the progressive reduction in quality of life. Studies show that patients with rheumatic diseases are more inactive than healthy controls [8-13, 15-17]. Rheumatoid arthritis, which is an inflammatory disease, and the non-inflammatory rheumatic diseases like osteoarthritis and fibromyalgia syndrome are recognized as the most common rheumatic diseases in Turkey $[18,19]$. Although epidemiologic studies on rheumatic diseases in Turkey are quite limited it is known that this group of patients (OA, FMS, RA) mostly experience pain and activity limitations, and frequently consults physiotherapy departments in Turkey. In our country, these groups of patients consult for the physiotherapy clinics in order to reduce pain and activity limitations [1921]. However, behavioral methods adapting and increasing the habit of physical activity are not usually included in rehabilitation programs. The new studies recommend that healthcare professionals should encourage people with rheumatic conditions to participate in regular physical activity to improve aerobic fitness and increase the quality of life [22]. The first step in this issue is to determine the level of physical activity in people with rheumatic disease. Nevertheless, there is surprisingly little research available comparing daily life physical activity between patients with rheumatic diseases and healthy controls. In the literature researchers have generally investigate the level of physical activity of the healthy population and some chronic diseases such as a cancer, obesity and cardiovascular diseases. Also large parts of the research have been designed regarding different exercise programs' effekt the symptoms of the disease in order to investigate the effectiveness of the physical activity programs [23-29]. To our knowledge, as yet, there is no study that investigates the physical activity levels of patients with rheumatic diseases. The main purpose of this study was to evaluate levels of the physical activity in patients with rheumatoid arthritis, osteoarthritis and fibromyalgia syndrome, and to compare the results with healthy subjects and each other.

\section{Materials and Methods}

\section{Participants}

50 rheumatoid arthritis patients, 95 osteoarthritis patients and 82 fibromyalgia patients aged 40-60 years, with a disease duration of $\geq 1$ year, according to the ACR criteria (American College of Rheumatology) at the Baskent University Hospital, Department of Physical Medicine and Rehabilitation outpatient clinics and 110 healthy subjects (control) of the same age group were consecutively enrolled into the study between September 2011 and May 2013 (> Fig. 1).

Exclusion criteria were: Neurological deficits, significant osteoporosis, severe negative consequences for physical and/or mental functioning, malignancy, severe cardio respiratory diseases, new passing operation of orthopedic, neurologic and other reasons, exacerbation period of rheumatoid arthritis patients, physical activity barriers, and being non-cooperative.

It was determined that the subjects included in the healthy group had not taken any medication.

The study was approved by the Ethics committee at Medicine and Health Sciences Research Council of Baskent University, Ankara, Turkey, reference number KA11 \227. Written informed consents were obtained from all the participants.

\section{Instruments}

1. Socio demographic characteristics were recorded as including age, sex, employment status, and education level categorized as low (primary school or intermediate school), intermediate (secondary school), and high (university). Disease duration and exercise habits, smoking habits and joint involvements were also recorded.

2. Pain was evaluated with the by the visual analogue scale (VAS) that shown a pain intensity measurement [30].

3. Physical activity assessment. 

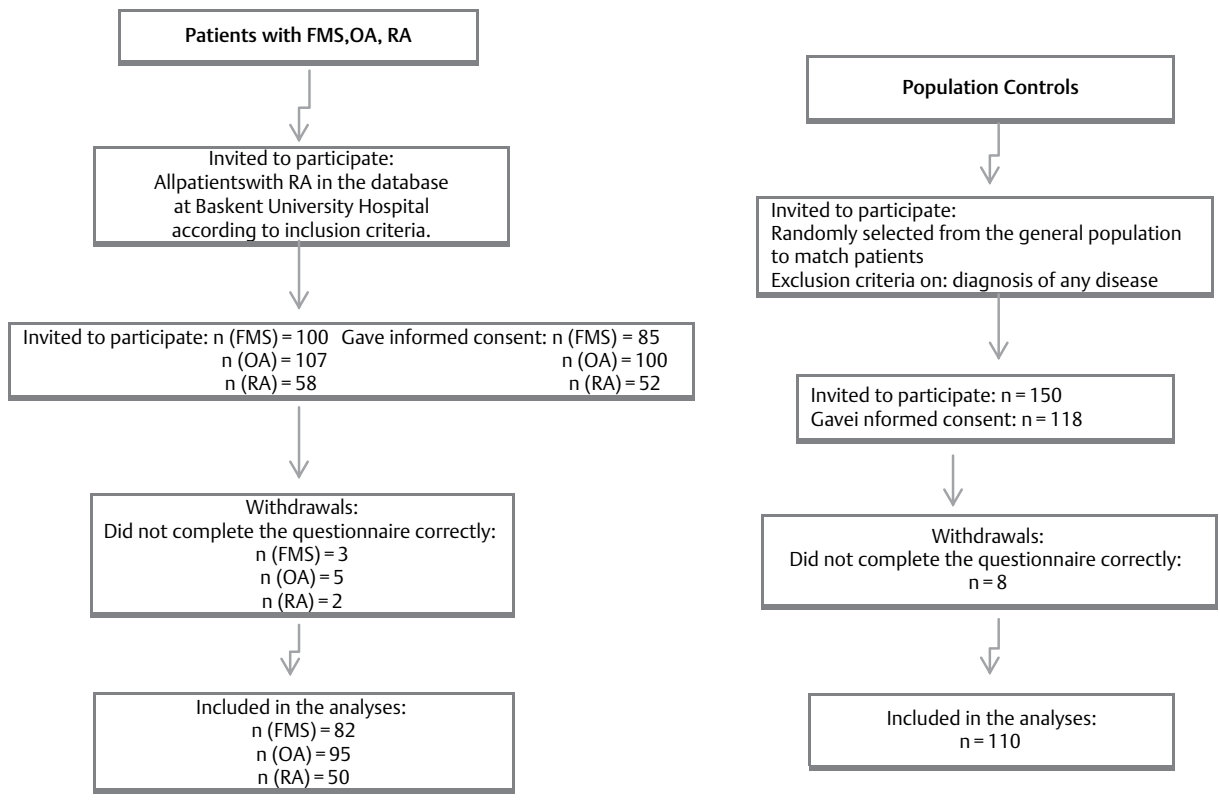

- Fig. 1 Flow of participant inclusion. FMS, OA, RA and CO. FMS=Fibromyalgia Syndrome, OA=Osteoarthritis, RA=Rheumatoid Arthritis $\mathrm{CO}=$ Control Groups.

Physical activity levels were evaluated by the Long Form of the International Physical Activity Questionnaire Turkish Version (IPAQ) [31]. The IPAQ long form consists of 27 questions. IPAQ is a scale to be recorded at different levels of physical activity time in the last week. It consists of 5 dimensions of physical activity; housework, work/occupation related, walking/bicycling, exercise, and leisure time activities as well as an open question about number of hours sitting per day. In each of the 4 domains the number of days per week and time per day spent in both moderate and vigorous activity are recorded. Practical examples of culturally relevant activities of moderate and vigorous intensity are given. In this study, moderate intensity was defined as 3-6 MET (Metabolic Equivalent Task) and vigorous intensity was defined as > 6 MET. One MET is equal to the energy expenditure during rest, and is approximately equal to $3.5 \mathrm{ml} \mathrm{O} 2 \mathrm{~kg}$ in adults. The outcome measures used were: MET hours per week and hours reported in moderate- and vigorous intensity activity per week. The PA data from the questionnaire was transformed into energy expenditure estimates as MET using published values. To calculate the weekly physical activity (MET-h/ week), the number of hours dedicated to each activity class was multiplied by the specific MET score for that activity. The individuals whose score is lower than 600 MET are described as inactive, between 600-1500 MET are described as minimal active and higher than 3000 MET are described as active [32].

\section{Statistical Analysis}

The results of tests were expressed as the number of observations (n), mean \pm standard deviation, median and min-max values. The results of the homogenity (Levene's Test) and normality tests (Shapiro Wilk) were used to decide which statistical methods to apply in the comparison of the study groups. Normally distributed and with homogeneous variances groups were compared 2 groups by Student's t test and compared 3 or more groups by Analysis of Variance (ANOVA). According to those tests results parametric test assumptions were not available for some variables, so the comparisons of 2 independent groups were performed by Mann-Whitney $U$ test, comparisons of three independent groups were performed by Kruskal Wallis test. Multiple comparison tests, the adjusted Bonferroni test was used. Categorical data was analysed with Fischer's Exact Test and Chi-square test. Expected to be less than $25 \%$ of cells in cases for inclusion in the analysis of those cells „Monte Carlo Simulation Method“ and the values were determined. All statistical analyses were performed with the SPSS software (SPSS Ver. 17.0; SPSS Inc., Chicago IL, USA). p value of $<0.05$ was considered statistically significant.

\section{Results}

\section{Characteristics of the participants:}

The patients' mean of gender, age, body mass index, and duration of disease, educational status, marital and employment status comparisons between the 4 groups are shown in $>$ Table 1 . There were significant differences between the groups in duration of disease and gender $(p<0.05)$. All the patients' mean age, body mass index, education level, and marital status were found to be similar $(p<0.05)$. The smoking and exercise habits of all groups are shown in $>$ Table $1.22 \%$ of fibromyalgia patients, $30 \%$ of rheumatoid arthritis patients, $34,7 \%$ of osteoarthritis patients, and $35,5 \%$ of healthy individuals had exercise habits. 
- Table 1 Physical and demographic characteristics on FMS, OA, RA and control group (CO).

\begin{tabular}{|c|c|c|c|c|c|c|}
\hline & FMS & OA & RA & CO & Total & $P$ value \\
\hline Cases Number n (\%) & $82(24,3)$ & $95(28,2)$ & $50(14,8)$ & $110(32,6)$ & 337 & \\
\hline \multicolumn{7}{|l|}{ Gender $\mathbf{n}$ (\%) } \\
\hline Female & $59(72)$ & $58(61,1)$ & $44(88)$ & $71(64,5)$ & $232(68,8)$ & 0,006 \\
\hline Male & $23(28)$ & $37(38,9)$ & $6(12)$ & $39(34,5)$ & $105(31,2)$ & \\
\hline Age $(X \pm S D)$ & $53,62 \pm 7,12$ & $52,98 \pm 6,83$ & $51,98 \pm 9,50$ & $51,7 \pm 8,37$ & $52,59 \pm 7,86$ & 0,365 \\
\hline BMi $(X \pm S D)$ & $27,26 \pm 4,13$ & $26,78 \pm 4,07$ & $25,66 \pm 3,23$ & $26,22 \pm 3,95$ & $26,55 \pm 3,95$ & 0,102 \\
\hline Duration of disease (years) $(X \pm S D)$ & $7,54 \pm 5,61$ & $7,61 \pm 5,37$ & $10,56 \pm 7,38$ & & & 0,008 \\
\hline \multicolumn{7}{|l|}{ Education Statue n (\%) } \\
\hline Primary School & $12(14.6)$ & $11(11.6)$ & $17(34.0)$ & $16(14.5)$ & & \\
\hline Secondary School & $13(15.9)$ & $20(21.1)$ & $4(8.0)$ & $5(13.6)$ & & \\
\hline High School & $16(19.5)$ & $28(29.5)$ & $14(28.0)$ & $40(36.4)$ & & 0,007 \\
\hline University & $38(46.3)$ & $31(32.6)$ & $14(28.0)$ & $38(34.5)$ & & \\
\hline Others & $3(3.7)$ & $5(5.3)$ & $1(2.0)$ & $1(.9)$ & & \\
\hline \multicolumn{7}{|l|}{ Martial Statue n (\%) } \\
\hline Married & $57(69,5)$ & $73(76,8)$ & $37(74,0)$ & $91(82,7)$ & & \\
\hline Single & $8(9,8)$ & $10(10,5)$ & $3(6,0)$ & $(7,3)$ & & \\
\hline Divorced & $5(6,1)$ & $3(3,2)$ & $4(8,0)$ & $3(2,7)$ & & 0,316 \\
\hline Widow & $12(14,6)$ & $9(9,5)$ & $5(10)$ & $8(7,3)$ & & \\
\hline Live separately & $0(0)$ & $0(0)$ & $1(2,0)$ & $0(0)$ & & \\
\hline \multicolumn{7}{|l|}{ Working Statue n (\%) } \\
\hline Working & $28(34,1)$ & $35(36,8)$ & $18(36,0)$ & $49(44,5)$ & & \\
\hline Not Working & $21(25,6)$ & $30(31,6)$ & $18(36,0)$ & $30(27,3)$ & & 0,481 \\
\hline Retiring & $33(40,2)$ & $30(31,6)$ & $14(28,0)$ & $31(28,2)$ & & \\
\hline Not Working Because Of Disease & $0(0)$ & $0(0)$ & $0(0)$ & $0(0)$ & & \\
\hline \multicolumn{7}{|l|}{ Smoking Statue $\mathbf{n}(\%)$} \\
\hline Smoking & $53(64,6)$ & $42(44,2)$ & $21(42,0)$ & $54(49,1)$ & & \\
\hline Not Smoking & $25(30,5)$ & $38(40,0)$ & $22(44,0)$ & $48(43,6)$ & & 0,029 \\
\hline Quit Smoking & $4(4,9)$ & $15(15,8)$ & $7(14,0)$ & $8(7,3)$ & & \\
\hline \multicolumn{7}{|l|}{ Exercise Habit n (\%) } \\
\hline Yes & $18(22,0)$ & $33(34,7)$ & $15(30,0)$ & $39(35,5)$ & & 0,935 \\
\hline No & $64(78,0)$ & $62(65,3)$ & $35(70,0)$ & $71(64,5)$ & & \\
\hline Pain (VAS) $(X \pm S D)$ & $5,05 \pm 2,58$ & $4,54 \pm 2,42$ & $4,67 \pm 2,42$ & & & 0,324 \\
\hline
\end{tabular}

$p \leq 0,05$. Values are reported as mean \pm standart deviation(SD) or number of participants (\%) unless otherwise specified. BMI = Body Mass İndex. FMS = Fibromyalgia Syndrome OA= Osteoarthritis RA = Rheumatoid Arthritis $C O=$ Control Groups.VAS = Visual Analogue Scale

\section{Comparison of Physical activity levels of patients with RA, OA and FMS}

$36.6 \%$ of the FMS group, $28.4 \%$ of the OA group, $38 \%$ of the RA group and $22.7 \%$ of the healthy subjects were found to be inactive. $45.1 \%$ of the fibromyalgia group, $42.1 \%$ of the osteoarthritis group, $46 \%$ of the rheumatoid arthritis group, and $36.4 \%$ of the healthy subjects were found to be insufficiently active ( $\triangleright$ Table $\mathbf{2}$ ).

There were no significant differences in all parameters in the IPAQ scores between the rheumatoid arthritis, osteoarthritis, and fibromyalgia patients $(p>0.05)$. $\triangleright$ Table 3 shows the mean values of the IPAQ scores and comparisons of the physical activity levels of the patients with rheumatic diseases.

\section{Comparisons between Rheumatic Diseases and Healthy Controls}

There were significant differences in walking physical activity scores in IPAQ between all groups compared with the healthy controls $(p<0.05)$. Table 4 shows the comparisons between rheumatic diseases and healthy controls. It was found that walking and total IPAQ scores were statistically lower than healthy controls in the FMS and RA groups $(p<0,05)$ while there were significant differences in walking physical activity scores in IPAQ between the osteoarthritis and control groups $(p=0.05)$. 


\section{Discussion}

A review of the literature found a limited body of research comparing physical activity levels in rheumatic diseases [12-16]. Our study was planned in such a way that our findings can draw attention to the importance of physical activity level in people with rheumatic diseases in Turkey and to direct clinical guidelines.

In a compilation study conducted in 2012, Tierney et al., reported that patients with RA can have lower physical activity levels than healthy individuals or normative data [12]. Elkan et al., evaluated physical activity levels of RA patients using short-form IPAQ and reported that $21 \%$ of RA population had low physical activity levels [35].

Similar to the studies in the literature, $38 \%$ of patients with RA evaluated in our study were found to be inactive and have lower physical activity levels than healthy individuals. A detailed analysis

- Table 2 Percentage of physical activity levels in FMS, OA, RA and CO.

\begin{tabular}{|l|c|c|c|c|}
\hline & FMS & OA & \multicolumn{1}{|c|}{ RA } & CO \\
\hline İnactivity n (\%) & $30(36,6)$ & $27(28,4)$ & $19(38,0)$ & $25(22,7)$ \\
\hline Moderate activity n (\%) & $37(45,1)$ & $40(42,1)$ & $23(46,0)$ & $40(36,4)$ \\
\hline Vigorous activity n (\%) & $15(18,3)$ & $28(29,5)$ & $8(16,0)$ & $45(40,9)$ \\
\hline
\end{tabular}

$\mathrm{p} \leq 0,05 ; \mathrm{FMS}=$ Fibromyalgia Syndrome $\mathrm{OA}=$ Osteoarthritis $\mathrm{RA}=$ Rheumatoid Arthritis $\mathrm{CO}=$ Control Groups. Number of participants $(\%)$ of our results revealed that active patients were those who had a better course of disease. It was found that joint pain was one of the most important complaints of RA patients and the severity of pain showed variations in a day or from day to day. It was observed that many patients limited the activities in which they have difficulty such as walking, housework and shopping, while some of them continued to perform their activities to fulfill their roles as mothers or employees, which increased their symptoms. Transport and leisure activities of RA patients, who even have to limit their daily life activities at home and at work, increasingly decrease. It can be stated that physical activity levels of RA patients gradually decrease when compared to healthy individuals due to activity limitations.

There is a limited body of research on the evaluation of physical activity levels of OA patients and majority of these studies focus on determining the factors affecting physical activity levels of knee and hip OA patients [26, 33-35]. Interestingly, although osteoarthritis has a higher prevalence than rheumatoid arthritis, the studies mostly concentrated on rheumatoid arthritis. Although numerous studies investigated the effects of exercise and physical activity on disease symptoms and physical aptitude in osteoarthritis patients, there is a limited body research on determining physical activity level $[20,23,24,34]$. A review of the studies analyzing physical activity levels of osteoarthritis patients revealed that the patients were 40 and older $[36,37]$. Since joint degeneration of osteoarthritis develop with old age. In our study, we determined inclusion criteria as the ages between 40 and 60 for rheumatoid arthritis and fibromyalgia patients groups in addition to osteoar-

- Table 3 Comparison of physical activity levels in FMS, OA, RA and CO.

\begin{tabular}{|c|c|c|c|c|c|}
\hline $\begin{array}{l}\text { IPAQ Sub parameters } \\
\text { MET-min/week }(X \pm S D)\end{array}$ & FMS & OA & RA & CO & $P$ value \\
\hline Walking PA & $1010,53 \pm 1589,57$ & $1349,44 \pm 2064,42$ & $1100,25 \pm 1623,51$ & $2175,22 \pm 3191,71$ & 0,030 \\
\hline Moderate PA & $993,87 \pm 1618,01$ & $890,19 \pm 1223,44$ & $597,00 \pm 1103,21$ & $1110,73 \pm 1997,24$ & 0,298 \\
\hline Vigorous PA & $308,76 \pm 935,02$ & $546,64 \pm 1701,76$ & $197,68 \pm 493,74$ & $1114,76 \pm 3643,97$ & 0,054 \\
\hline Total PA & $2257,15 \pm 3081,29$ & $2732,91 \pm 3314,97$ & $1817,91 \pm 2060,75$ & $4137,30 \pm 6595,91$ & 0,060 \\
\hline
\end{tabular}

$\mathbf{p} \leq \mathbf{0 , 0 5}$. FMS $=$ Fibromyalgia Syndrome $\mathrm{OA}=$ Osteoarthritis $\mathrm{RA}=$ Rheumatoid Arthritis $\mathrm{CO}=$ Control Groups. Values are reported as mean \pm standart deviation (SD). IPAQ = International Physical Activity Questionnaire. MET-min/week= Metobolic Equivalent- (Minute/Week). PA=Physical Activity

- Table 4 p value of physical activity levels between rheumatic diseases and CO.

\begin{tabular}{|c|c|c|c|c|c|c|c|}
\hline & $\begin{array}{l}\text { FMS-OA } \\
\text { p value }\end{array}$ & $\begin{array}{l}\text { FMS-RA } \\
\text { P value }\end{array}$ & $\begin{array}{l}\text { OA-RA } \\
\text { P value }\end{array}$ & $\begin{array}{l}\text { OA-FMS } \\
\text { p value }\end{array}$ & $\begin{array}{l}\text { FMS-CO } \\
\text { p value }\end{array}$ & $\begin{array}{l}\text { RA-CO } \\
\text { p value }\end{array}$ & $\begin{array}{l}\mathrm{OA}-\mathrm{CO} \\
\mathrm{p} \text { value }\end{array}$ \\
\hline Walking PA & 0,999 & 0,999 & 0,999 & 0,999 & 0.005 & 0,047 & 0,005 \\
\hline Moderate PA & 0,999 & 0,999 & 0,999 & 0,999 & 0,999 & 0,372 & 0,999 \\
\hline Vigorous PA & 0,999 & 0,999 & 0,999 & 0,999 & 0,119 & 0,178 & 0,599 \\
\hline Total PA & 0,999 & 0,999 & 0,999 & 0,999 & 0,029 & 0,020 & 0,076 \\
\hline
\end{tabular}

$\mathbf{p} \leq \mathbf{0 , 0 5}$. FMS = Fibromyalgia Syndrome $\mathrm{OA}=$ Osteoarthritis $\mathrm{RA}=$ Rheumatoid Arthritis $\mathrm{CO}=$ Control Groups. $\mathrm{PA}=$ Physical Activity 
thritis, to include patients with similar age groups. Our study included individuals at this age group.

In their study to determine the factors affecting physical activity, Rosemann et al., evaluated patients with osteoarthritis in lower extremities using IPAQ. The researchers found that $55 \%$ of patients were inactive, $38 \%$ were slightly active and $7 \%$ were active. They reported that physical activity levels of OA patients were lower than those of healthy population and that increasing physical activity was important in treatment. There are a few studies carried out in Turkey to evaluate physical activity levels of osteoarthritis patients. These studies reported that physical activity levels of OA patients were low $[38,39]$.

Evaluation of physical activity level of osteoarthritis patients in our study showed that $28 \%$ were inactive, $42 \%$ were minimal active and $29 \%$ were active. In Turkey, osteoarthritis patients are admitted to physiotherapy clinics generally due to the complaints of pain and activity limitation. While the physiotherapist evaluate normal joint movement and muscle force in involved joint region, evaluation of physical activity level and suggestions for physical activity are generally overlooked. Patients should acquire the habit of doing regular physical activity.

A wide range of symptoms such as low pain threshold, sleep disorders, fatigue, anxiety, depression, decreased physical function capacity accompany the disease in patients with FMS. It is reported that this limitation can result from decreased physical activity level [40]. Therefore, it is important to evaluate physical activity level when determining treatment program for FMS patient group. While much of the literature focused on the relationship between physical activity and health, some studies focused on determining physical activity suggestions and analyzing the factors affecting physical activity. McLoughlin et al., compared physical activity levels of FMS patients and healthy individuals using IPAQ and found that FMS patients were less physically active than healthy individuals. They found statistically significant differences in IPAQ walking, severe and total scores [41].

In our study, we evaluated physical activity levels of FMS patients using IPAQ. We found that $37 \%$ of the patients were inactive. Comparison of FMS patients and healthy individuals showed a statistically significant difference in IPAQ walking and total scores. FMS patients were found to be less physically active than healthy individuals.

A review of the literature showed only a few studies comparing physical activity levels of RA, OA and FMS patients. In their study conducted in 2006, Grene et al., analyzed the factors affecting physical activity levels of rheumatoid arthritis and osteoarthritis patients and recorded sitting-reaching, exercise, housework and leisure activities in a day using Physical Activity and Disability Survey (PADS). The researchers found that RA patients had higher leisure activity times than OA patients [42]. Raftery et al., on the other hand, evaluated physical activity level of FMS and RA patients using accelerometer and reported that physical activity levels of 2 groups were similar [43].

Comparison of RA, FMS and OA groups in our study showed similar physical activity levels. The patients in all three groups are believed to have similar low physical activity levels since they avoid physical activity fearing that it will increase pain and fatigue complaints and since they are not provided adequate suggestions for physical activity.

\section{Conclusion}

The importance of physical activity in healthy individuals and patients with chronic diseases has been emphasized in recent years in Turkey. Ministry of Health carries out studies regarding physical activity in chronic diseases (diabetes, hypertension, coronary diseases usw.) in adult, pediatric and geriatric individuals [27-29]. However, it was observed that both patients and healthcare personnel are unconscious towards physical activity in rheumatic diseases. Healthcare professionals such as rheumatologists, physiotherapists, rheumatology nurses should provide guidance to increase physical activity with a multidisciplinary approach to help patients have a healthy life style. Our study evaluated physical activity levels in rheumatoid arthritis, osteoarthritis and fibromyalgia patients and showed that physical activity levels were low in these patient groups. This study is believed to draw attention to the importance of physical activity in rheumatic diseases and to contribute to formation of clinical guidelines in the future.

\section{Conflict of interest}

None.

References

[1] Kodama S, Saito K, Tanaka S et al. Cardiorespiratory fitness as a quantitative predictor of all-cause mortality and cardiovascular events in healthy men and women: a meta analysis. JAMA 2009; 301: 2024-2035

[2] Blair SN. Physical inactivity: The biggest public health problem of the 21st century. Br J Sports Med 2009; 43: 1-2

[3] Westerterp KR. Assessment of physical activity: a critical appraisal. Eur J Appl Physiol 2009; 105: 823-828

[4] Vanhees L, Lefevre J, Philippaerts R. How to assess physical activity? How to assess physical fitness? Eur J Cardiovasc Prev Rehabil 2005; 12 : 85-86

[5] Bonomi AG, Goris AH, Yin B et al. Detection of type, duration, and intensity of physical activity using an accelerometer. MedSci Sports Exerc 2009; 41: 1770-1777

[6] Sallis JF, Saelens BE. Assessment of physical activity byself-report:Status, limitations, and future directions. Res Q Exerc Sport 2000; 71: S1-S14

[7] Hootman JM, Helmick CG, Schappert SM. Magnitude and characteristics of arthritis and other rheumatic conditions on ambulatory medical care visits. Arthritis Rheum 2002; 47: 571-581

[8] Hootman JM, Macera CA, Sam HA. Physical activity levels among the general US adult population and in adults with and without arthritis. Arthritis Rheum 2003; 49: 129-135

[9] Sokka T, Häkkinen A, Kautiainen $\mathrm{H}$ et al. Physical inactivity in patients with rheumatoid arthritis: data from twenty-one countries in a cross-sectional, international study. Arthritis Rheum 2008; 59: 42-50

[10] Eurenius E, Stenstrom CH. Physical activity, physical fitness, and general health perception among individuals with rheumatoid arthritis. Arthritis Rheum 2005; 53: 48-55

[11] Van den Berg MH, De Boer IG, le Cessi S et al. Are patients with rheumatoid arthritis less physically active than the general population? J Clin Rheumatol 2007; 13: 181-186

[12] Tierney M, Fraser A, Kennedy N. Physical Activity in Rheumatoid Arthritis. A Systematic Review. JPAH 2012; 9: 1036-1048 
[13] Cieza A, Ewert T, Ustun TB et al. Development of ICF core sets for patients with chronic conditions. J Rehabil Med 2004; 44: 9-11

[14] Dunlop DD, Semanik P, Song J et al. Moving to maintain function in knee osteoarthritis: Evidence from the osteoarthritis initiative. Arch Phys Med Rehabil 2010; 91: 714-721

[15] Hutton I, Gamble G, McLean G et al. What is associated with being active in arthritis? Analysis from the Obstacles to Action study. Intern Med J 2010; 40: 512-520

[16] Gyurcsik NC, Brawley LR, Spink KS et al. Physical activity in women with arthritis: examining perceived barriers and self-regulatory efficacy to cope. Arthritis Rheum 2009; 61: 1087-1094

[17] Ruiz J, Segura-Jeminez V, Ortega F et al. Objectively measured sedentary time and physical activity in women with fibromyalgia: a cross-sectional study. BMJ Open 2013; 3: e002722 doi:10.1136/ bmjopen-2013-002722

[18] Hootman JM, Bolen J, Helmick C et al. Prevalence of doctor-diagnosed arthritis and arthritis-attributable activity limitation. Morb Mortal Wkly Rep 2006; 55: 1089-1092

[19] Hamuryudan V. Common diseases in Turkey. (Infectious disease, rheumatic diseases) Symposium Series. Istanbul University Cerrahpasa medicine 2007; 55: 69-86

[20] Gur H, Cakin N. Muscle mass, isokinetic torque, and functional capacity in women with osteoarthritis of the knee. Archives of Physical Medicine and Rehabilitation 2003; 84: 1534-1541

[21] Çetin N. Factors affecting the quality of life in patients with fibromyalgia. Turk J Rheumatol 2009; 24: 77-81

[22] Hammond A, Jeffereson P. Rheumatoid Arthritis. In: Turner A, Foster M, Jhonson S.E.(ed.). Occupational Therapy and Physical Dysfunction; principles, skills and practise. $5^{\text {th }}$ (ed.). Edinburgh: Churchill; Livingston: 2002

[23] De Groot IB, Bussmann JB, Stam HJ et al. Actual every day physical activity in patients with end-stage hip or knee osteoarthritis compared with healthy controls. Osteoarthritis Cartilage 2008; 16: 436-442

[24] Dogu B, Sirzai H, Yilmaz F et al. Effects of isotonic and isometric hand exercises on pain, hand functions, dexterity and quality of life in women with rheumatoid arthritis. Rheumatol Int 2013; 33: 26252630

[25] Hernández V, Ferraz-Amaro I, Díaz-Gonzá lez F. Influence of disease activity on the physical activity of rheumatoid arthritis patients. Rheumatology 2014; 53: 722-731

[26] Stubbs B, Hurley M, Smith T. What are the factors that influence physical activity participation in adults with knee and hip osteoarthritis? A systematic review of physical activity correlates. Clinical Rehabilitation 2014; 1-15

[27] Dashti D, Esfehani A, Joseph HJ. The preventive effect of physical activity on weight maintenance in overweight and obese women. Clin Ther 2014; 165: 155-156
[28] Khoja SS, Susko AM, Josbeno DA et al. Comparing physical activity programs for managing osteoarthritis in overweight or obese patients. J Comp Eff Res 2014; 3: 283-299

[29] Berry NM, Miller MD, Woodman RJ et al. Differences in chronic conditions and lifestyle behaviour between people with a history of cancer and matched controls. Med J Aust 2014; 201: 96-100

[30] Collins SL, Moore RA, McQuay HJ. The visual analogue pain intensity scale: what is moderate pain in millimetres? Pain 1997; 72: 95-97

[31] Sağlam M, Arıkan H, Savcı S. International Physical Activity Questionnaire. Realiability and Validity of the Turkish Version; Perceptual and motor skills 2010; 11: 278-284

[32] Craig CL, Marshall AL, Sjostrom M et al. International physical activity questionnaire: 12 -country reliability and validity. Med Sci Sports Exerc 2003; 35: 1381-1395

[33] Vignon E, Valat JP, Rossignol M. Osteoarthritis of the knee and hip and activity: a systematic international review and synthesis (OASIS). Joint Bone Spine 2006; 73: 442-557

[34] Dunlop DD, Semanik P, Song J et al. Risk factors for functional decline in older adults with arthritis. Arthritis Rheum 2005; 52: 1274-1282

[35] Dunlop DD, Song J, Semanik PA et al. Physical activity levels and functional performance in the osteoarthritis initiative: a graded relationship. Arthritis Rheum 2011; 63: 127-136

[36] Elkan AC, Håkansson N, Frostegård J et al. Low level of physical activity in women with rheumatoid arthritis is associated with cardiovascular risk factors but not with body fat mass. BMC Musculoskeletal Disorders 2011; $12: 13$

[37] Blagojevic M, Jinks C, Jeffery A et al. Risk factors for onset of osteoarthritis of the knee in older adults: a systematic review and meta-analysis. Osteoarthritis Cartilage 2010; 18: 24-33

[38] Oliveria SA, Felson DT, Reed JI et al. Incidence of symptomatic hand, hip, and knee osteoarthritis among patients in a health maintenance organization. Arthritis Rheum 1995; 38: 1134-1141

[39] Rosemann T, Kuehlein T, Laux G et al. Factors associated with physical activity of patients with osteoarthritis of the lower limb. J Eval ClinPract 2008; 14: 288-293

[40] Kaleth AS, Saha CK, Jensen MP et al. Effect of moderate-vigorous physical activity improves long-term clinical outcomes and worsening pain severity in fibromyalgia. Arthritis Care and Research 2013; 65: $1211-1218$

[41] Mc Loughlin MJ, Colbert LH, Stegner AJ et al. Are women with fibromyalgia less physically active than healthy women? Med Sci Sports Exerc 2011; 43: 905-912

[42] Greene BL, Haldeman GF, Kaminski A et al. Factors affecting physical activity behavior in urban adults with arthritis who are predominantly African-American and female. PhysTher 2006; 86: 510-519

[43] Raftery G, Bridges M, Heslop P et al. Are fibromyalgia patients as inactive as they say they are? Clin Rheumatol 2009; 28: 711-714 